\title{
Rhinology future trends: 2017 EUFOREA debate on allergic rhinitis*
}

\author{
Glenis Scadding1, Jean Bousquet ${ }^{2-4}$, Claus Bachert ${ }^{5,6}$, Wytske Fokkens $^{7}$, \\ Peter W. Hellings ${ }^{7,8}$, Emmanuel Prokopakis ${ }^{9}$, Oliver Pfaar ${ }^{10,11}$, David Price ${ }^{12,13}$ \\ Rhinology 57: 1, 49 - 56, 2018 \\ https://doi.org/10.4193/Rhin18.076 \\ 'The Royal National Throat Nose \& Ear Hospital, Gray's Inn Road, London, UK \\ *Received for publication: \\ ${ }^{2}$ MACVIA-France and Foundation FMC VIA -LR, Montpellier, France \\ April 6, 2018 \\ ${ }^{3}$ INSERM U 1168, VIMA: Ageing and Chronic Diseases Epidemiological and Public Health Approaches, Villejuif, Université Versailles Accepted: May 18, 2018 \\ St-Quentin-en-Yvelines, UMR-S 1168, Montigny le Bretonneux, France \\ ${ }^{4}$ CHU Montpellier, 371 Avenue du Doyen Gaston Giraud, 34295 Montpellier Cédex 5, France \\ ${ }^{5}$ Ghent University Hospital, Belgium \\ ${ }^{6}$ Karolinska Institute, Stockholm, Sweden \\ ${ }^{7}$ Department of Otorhinolaryngology, Academic Medical Centre, Amsterdam, The Netherlands \\ ${ }^{8}$ Clinical Division of Otorhinolaryngology, Head and Neck Surgery, University Hospitals Leuven, Leuven, Belgium \\ ${ }^{9}$ Department of Otorhinolaryngology, University of Crete School of Medicine, Heraklion, Greece \\ ${ }^{10}$ Department of Otorhinolaryngology, Head and Neck Surgery, Universitätsmedizin Mannheim, Medical Faculty Mannheim, \\ Heidelberg University, Mannheim, Germany \\ "Center for Rhinology and Allergology, Wiesbaden, Germany \\ ${ }^{12}$ Centre of Academic Primary Care, University of Aberdeen, Aberdeen, UK \\ ${ }^{13}$ Observational and Pragmatic Research Institute, Singapore
}

\begin{abstract}
The 2nd Rhinology Future Debate, organized by EUFOREA (European Forum for Research and Education in Allergy and Airways diseases) was held in Brussels in December 2017. One of these debates addressed the position of MP-AzeFlu in allergic rhinitis (AR) treatment. The current article summarizes this debate; reviewing recent data, and exploring how this has been interpreted by experts and incorporated into AR management guidelines and a clinical decision support system (CDSS). The Allergic Rhinitis \& its Impact on Asthma (ARIA) guideline position MP-AzeFlu firstline for the treatment of AR, and in preference to intranasal corticosteroids (INSs) during the first 2 weeks of treatment. The AR CDSS recommends MP-AzeFlu as one of the firstline treatments for patients with a visual analogue scale (VAS) score $<5 / 10 \mathrm{~cm}$, and in preference (along with INS) for those with a VAS score $\geq 5 / 10$ $\mathrm{cm}$. Panellists agreed that AR management should be kept as simple as possible, with some preferring a'one treatment fits all approach', while others preferred a step-up approach. The need to change the AR management mentality was acknowledged, accepting that most patients use their medication as needed and use multiple treatments; AR medications are needed which have a very fast onset of action and which target breakthrough symptoms. Panellists agreed that MP-AzeFlu has a role to play here, since it has a 5 minute onset-of-action, provides clinically-relevant symptom relief in 15 mins and AR control in $<3$ days, targets nasal hyper-reactivity (NHR) which likely contributes to uncontrolled AR and breakthrough symptoms, and provides more effective AR symptom relief than INS monotherapy or INS + oral antihistamine. Finally, experts considered it likely that MP-AzeFlu should have a greater impact on asthma control than INS in co-morbid patients, but clinical data is required to back up existing pharmacoeconomic evidence. The next Rhinology Future Debate will be in held in Brussels in Dec 2019.
\end{abstract}

Key words: allergic rhinitis, asthma, guidelines, nasal hyperresponsiveness, patient preference, MP-AzeFlu

\section{Introduction}

The Rhinology Future Debates is a clinician-orientated meeting that has been established to fill a gap with regard to industryinvestor meetings in the field of rhinology. The meeting focuses on all aspects of global innovation in rhinologic devices, diagnostics and biologicals, connecting scientists, physicians, regulators, corporate leaders, venture capitalists and other investors. The debates are organized by the European Forum for Research 


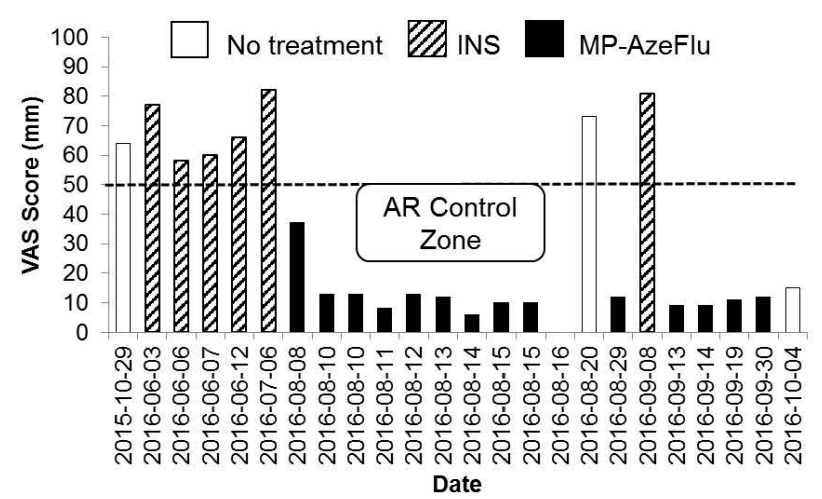

Figure 1. Individual user data from Allergy Diary showing visual analogue scale (VAS) score on allergic rhinitis (AR) treatment. INS: intranasal corticosteroid; MP-AzeFlu (intranasal azelastine/fluticasone propionate in single spray; Dymista $\left.{ }^{\circledR}\right)$.

and Education in Allergy and Airway Diseases (EUFOREA), which aims to reduce the preventable and avoidable burden of morbidity and disability due to chronic airway diseases ${ }^{(1-3)}$. EUFOREA brings together specialists from the entire healthcare system to create opportunities for innovative thinking and development of new techniques, devices, protocols and concepts.

The second Rhinology Future Debate took place in Brussels in December 2017 and brought together key experts in the field of respiratory diseases, industrial partners and patients for a discussion forum in the rhinology/respiratory field. Debate topics included (i) prevention of asthma by allergen-specific immunotherapy, (ii) nasal turbinate as a therapeutic target, (iii) biologicals in asthma (2017 update), and (iv) positioning of MP-AzeFlu (Dymista ${ }^{\circledR}$, Mylan Inc., USA) in allergic rhinitis (AR) treatment. These debates were recorded and are available via the EUFOREA (www.euforea.eu) and Rhinology Future websites (www.rhinology-future.com).

The aim of the current article is to summarize the MP-AzeFlu debate, reviewing recent data, exploring how this has been interpreted by experts and incorporated into AR management guidelines and clinical decision support systems (CDSSs). MP-AzeFlu comprises an intranasal anti-histamine (i.e. azelastine (AZE)), an intranasal corticosteroid (INS; i.e. fluticasone propionate (FP)) and a novel formulation delivered in a single spray (e.g. larger spray volume, finer droplet size distribution, and lower viscosity versus marketed FP products) ${ }^{(4,5)}$. Its efficacy and safety have been assessed in a large clinical development programme conducted in the U.S., Europe and Asia ${ }^{(6-10)}$. In Europe, it is indicated for the relief of symptoms of moderate-to-severe seasonal AR and perennial AR if monotherapy with either intranasal antihistamine or glucocorticoid is not considered sufficient ${ }^{(4)}$.

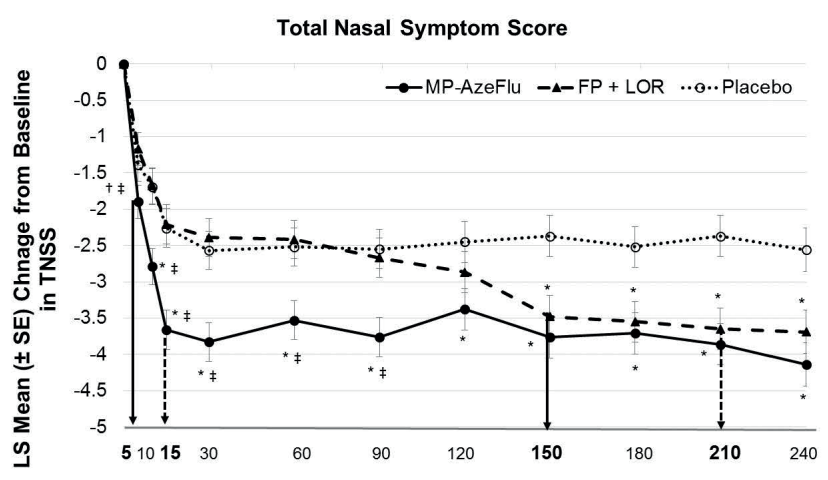

Figure 2. Effect of MP-AzeFlu (MP-azelastine/fluticasone propionate; Dymista $^{\circledR}$ ), FP (fluticasone propionate; Flonase ${ }^{\circledR}$ ) + LOR (loratadine; Claritin $^{\oplus}$ ) and placebo on change from baseline in total nasal symptom score (TNSS) assessed over a period of 4 hours following exposure to ragweed pollen in an allergen exposure chamber. Arrow: onset of action; dotted arrow: onset to clinically relevant effect compared to placebo (i.e. 1.17 change in TNSS). MP-AzeFlu (1 spray/nostril; $138 \mu \mathrm{g} / 50 \mu \mathrm{g}$ ); FP (1 spray/nostril; 50 Mg) + LOR (10 mg). LS: least squares; SE: standard error. ${ }^{*} \mathrm{p} \leq 0.005$ vs placebo; $\dagger \mathrm{p}=0.038$ vs placebo; $\neq \mathrm{p} \leq 0.003$ vs FP $+\mathrm{LOR}$. Modified from Bousquet et al, $2017^{(26)}$.

\section{Positioning of MP-AzeFlu in AR treatment}

There are many classes of medication available for the treatment of AR, ranging from leukotriene receptor antagonists, chromones and anti-histamines (oral \& topical), to INS, and combination intranasal therapies delivered in a single device (e.g. MP-AzeFlu) ${ }^{(11-14)}$. Some of these are only available on prescription, but many are available over the counter at pharmacies, making self-management a common practice in AR. Unfortunately, AR control remains poor for many patients ${ }^{(15,16)}$, with most resorting to poly-pharmacy (most commonly an oral anti-histamine + INS) in an effort to achieve better and faster nasal and ocular symptom relief ${ }^{(17-20)}$. This practice of adding an oral anti-histamine to an INS is neither endorsed by the scientific evidence ${ }^{(21,22)}$ nor by the latest ARIA (Allergic Rhinitis \& its Impact on Asthma) update, which does not recommended it at all for perennial $A R$, and acknowledges that for seasonal AR, the potential net benefit would not justify spending additional resources ${ }^{(13)}$. AR sufferers have a strong preference for an AR treatment which provides complete and rapid symptom relief and has a fast onset of action ${ }^{(23)}$. Patients' AR treatment behaviour in real life may be explained by these preferences. Data from an AR app for patients, called Allergy Diary (www.euforea.eu/innovation/allergy-diary. html) ${ }^{(24,25)}$ show how users do not take AR treatment every day, rapidly switch from one $A R$ treatment to another, achieve $A R$ control on more effective AR therapies (e.g. MP-AzeFlu), but then stop taking it or step down when symptoms are well controlled, and start treatment again when symptoms return (Figure 1). An AR treatment which provides rapid complete relief with a rapid 


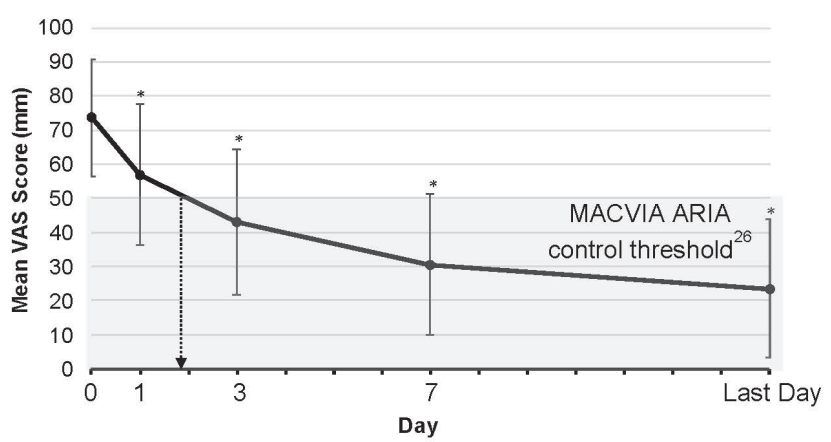

Figure 3. Effect of MP-AzeFlu (MP-azelastine/fluticasone propionate; Dymista $^{\circledR}$ ) on the visual analogue scale (VAS) score over time in 2756 patients with moderate-to-severe allergic rhinitis. Data are presented as mean (standard deviation) ${ }^{*} \mathrm{p}<0.001$ versus baseline. Modified from Klimek et al., $2016^{(10)}$.

onset of effect would accommodate patient treatment behaviour in real-life.

MP-AzeFlu has many of the attributes sought by patients from an AR treatment. Firstly, it has a 5 minute onset of action, the most rapid of any AR treatment, compared to 150 minutes for a loose combination of FP and oral loratadine (LOR: Figure 2), and is significantly more effective than FP + LOR over a $4 \mathrm{~h}$ time fame ${ }^{(26)}$. Furthermore, MP-AzeFlu achieved a clinically relevant effect at 15 mins versus 210 mins for FP + LOR ${ }^{(26)}$. Secondly, MP-AzeFlu provides rapid and sustained AR control in real life, assessed using a visual analogues scale (VAS) and the $5 / 10 \mathrm{~cm}$ cut-off recommended by MACVIA ARIA ${ }^{(10,27)}$. Patients treated with MP-AzeFlu crossed this MACVIA-ARIA control cut-off before Day 3, and over $90 \%$ of patients considered their symptoms to be well- or partly-controlled at that time point (Figure 3) ${ }^{(10)}$. Thirdly, MP-AzeFlu provides relief from both nasal and ocular symptoms associated with AR, being twice as effective as an INS or intranasal anti-histamine for overall relief (Figure 4) ${ }^{(7)}$. It also targets patients' most bothersome symptoms, being 54\% and $67 \%$ more effective than FP for nasal congestion and ocular itch relief, respectively ${ }^{(7)}$. This is an important finding since patients consider nasal congestion to be their most bothersome nasal symptom, as it affects mood, sleep and productivity ${ }^{(28)}$, whereas ocular symptoms have the greatest negative impact on quality of life ${ }^{(16)}$. Finally, MP-AzeFlu provides complete symptom relief for many patients, and does so approximately a week faster than FP or AZE monotherapy ${ }^{(7)}$.

MP-AzeFlu has been positioned in the guidelines based on these data ${ }^{(13,14,29)}$. According to the British Society of Allergy and Clinical Immunology guidelines, MP-AzeFlu is recommended for AR patients who have failed anti-histamine or INS therapy (after

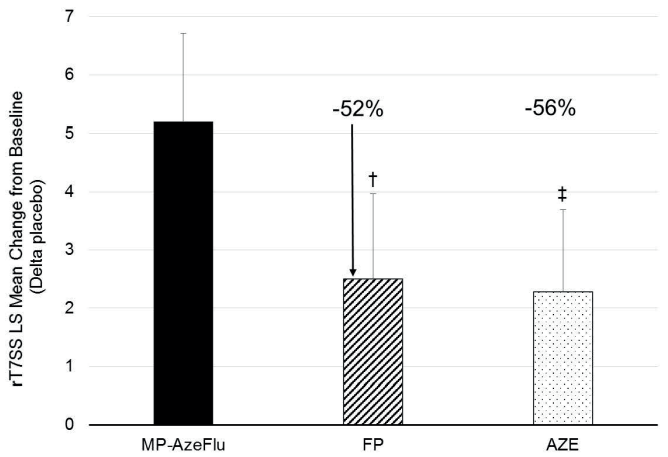

Figure 4. Effect of treatment with MP-AzeFlu (MP-azelastine/fluticasone; Dymista ${ }^{\oplus}$; $=153$ ), fluticasone propionate (FP; $n=151$ ) or azelastine (AZE; $\mathrm{n}=152$ ) for 14 days (all 1 spray/nostril bd) on overall change from baseline in reflective total of 7 symptom scores (rT7SS) in patients with moderate/severe AR. $+p=0.013$ vs MP-AzeFlu; $\neq p=0.0004$ vs MP-AzeFlu. LS: least squares. Produced using tabular data from Meltzer et al., $2013^{(7)}$.

checking for use, concordance and dose) ${ }^{(14)}$. Considering that most AR patients with moderate-severe disease have been, or are currently, on an AR treatment, with $70 \%$ using multiple therapies ${ }^{(17)}$, this population represents the majority of AR patients visiting their physicians. ARIA position MP-AzeFlu firstline for the treatment of $A R$, and in preference over INS during the first 2 weeks of treatment, due to faster response ${ }^{(13)}$. This position is backed up by the AR clinical decision support system, which recommends MP-AzeFlu as one of the firstline AR treatment options for those with a VAS score $<5$, and in preference (along with INS) for those with a VAS score $\geq 5^{(27)}$.

\section{Debate}

Interpretation of how MP-AzeFlu should be prescribed Like the guidelines themselves, opinion on the positioning of MP-AzeFlu within them, and how it should be used to manage $A R$ in clinical practice varied amongst the panel members. There was a general consensus that AR management should be kept as simple as possible, with treatment chosen on the basis of severity, medical history (including the presence of nasal hyperreactivity (NHR)), efficacy, onset and patient preference. Some experts preferred a 'one treatment fits all approach'; treating with the most effective medication immediately to obtain disease control, and sticking with that medication, without adding the complexity of stepping up and stepping down (Table 1). MP-AzeFlu fits this approach well, being the most effective symptomatic treatment for $\mathrm{AR}$, targeting both nasal and ocular symptoms ${ }^{(7)}$ as well as $\mathrm{NHR}^{(30)}$, and also providing rapid and sustained control in real life ${ }^{(10)}$. Others considered that AR treatment should be proportionate, recognizing that many patients obtain sufficient symptom relief on oral anti-histamines or INS. Rather, MP-AzeFlu should be reserved for those AR patients 
who need it, matching the treatment to the patient, while at the same time managing healthcare costs (Table 1). Within this opinion was the acknowledgment that most patients visiting their doctor have moderate-to-severe AR and have tried many other AR treatments, with most using multiple therapies ${ }^{(17,31)}$. Finally, others questioned the need for guidelines, highlighting the necessity to fulfil the needs and treatment behaviour of the patient and not the wishes of physicians. Currently, 9000 users from 23 countries use the Allergy Diary app to monitor their AR control and treatment ${ }^{\left({ }^{32}\right)}$. What is clear from the data derived from this app is that only $4 \%$ of users are taking their AR medication regularly. There is, therefore, a need to change our mentality regarding AR management, towards an acceptance of an 'as needed approach' to AR medication use (in the vast majority of cases) and, as a consequence, towards AR medications which have a very fast onset of action and which target breakthrough symptoms. In the future there may be a move away from guidelines towards change management. AR management is currently changing. Change occurs continuously around us, and can be challenging. At its best, it should be effective and combine both technological and people-orientated solutions ${ }^{(33)}$. Effective change has been characterized as unfreezing old behaviours, introducing new ones and re-freezing them ${ }^{(33)}$. Perhaps it's time to unfreeze old AR management principles, incorporate novel technologies and patient behaviour into a new approach?

The experts agreed that clarity on MP-AzeFlu positioning within the guidelines would be facilitated by robust health economic data. In the EU, avoidable costs per patient insufficiently treated for allergy range between $€ 55$ and $€ 151$ billion per annum due to absenteeism and presenteeism ${ }^{(34)}$. A potential saving of $€ 142$ billion could be made each year in the EU by appropriately treating allergic disease ${ }^{(34)}$. ARIA acknowledge that appropriate treatment of AR improves symptoms, quality of life as well as work and school performance ${ }^{(13)}$. MP-AzeFlu could potentially save the European health economy billions every year as it is the fastest acting therapy ${ }^{(26)}$, is twice as effective as INS ${ }^{(7)}$ (previously considered the most effective symptomatic treatment option) ${ }^{(11,12)}$, provides AR control in 3 days ${ }^{(10)}$ and significantly reduces $\mathrm{NHR}{ }^{(30)}$. NHR is present in up to two thirds of patients ${ }^{(35)}$, and a potential cause of breakthrough symptoms on treatment reported by AR patients ${ }^{(36,37)}$. Moreover, MP-AzeFlu may reduce AR-related costs ${ }^{(38)}$. Health-economic data from a commercially insured database in the U.S. showed that for AR patients needing an intranasal anti-histamine and an INS, MP-AzeFlu had better economic outcomes than for patients who rely on the free combination of these agents, with significantly lower ARrelated pharmacy costs noted in the MP-AzeFlu cohort ( $\$ 128 \mathrm{vs}$ $\$ 268)^{(38)}$. MP-AzeFlu also appeared to keep asthma-related utilization and costs down for asthma and AR co-morbid patients, associated with a reduction in pharmacy-and total-costs by $79 \%$ and $56 \%$, respectively, compared to the loose combination ${ }^{(38)}$.

\section{Patient preference}

Frank and open discussion with AR patients, in the doctor's office or at the pharmacy, is key to achieving good disease control. Providing patients with the information necessary to make an informed choice about their AR therapy and actively including them in the decision making process are fundamental to the principles of patient empowerment ${ }^{(39)}$. As physicians, we are often guilty of trying to impose on patients what they need, rather than on what they want. Patient preferences and expectations for AR treatment differ, and we should respect that. Some patients prefer an oral anti-histamine for example, while others prefer an intranasal therapy or to start with the most effective therapy available in order to quickly achieve control ${ }^{(40)}$. Other surveys have shown that AR sufferers have a strong preference for a treatment which provides complete symptom relief and has a fast onset of action ${ }^{(23,36)}$, and specifically for nasal sprays they want a favourable safety profile and the ability to use it 'as needed' ${ }^{\prime 36)}$. However, it was recognized that predictors of success of treatment, are also important to patients. Prediction of success with MP-AzeFlu is evident from its clinical trial data (e.g. 1 in 2 patients achieve substantial symptom relief) ${ }^{(7)}$, real life data (e.g. 1 in 2 patients feel their AR is well-controlled by Day 3) ${ }^{(10)}$ and chamber study data (e.g. 5 min onset of action) ${ }^{(26)}$. MPAzeFlu is not indicated for prn use ${ }^{(4)}$, but data form the Allergy Diary show that this is how AR sufferers take it, as well as other AR medications ${ }^{(19)}$. In real life, AR control is achieved rapidly with MP-AzeFlu, even when not used continuously as recommended (Figure 1), a testament to MP-AzeFlu's efficacy and onset of action profile. These data should be confirmed in a clinical trial setting. Recognizing which patients are likely to respond best to which treatments will improve AR management (Table 1).

\section{Nasal hyperresponsiveness: a neglected clinical feature of} AR

NHR is present in up to two-thirds of AR patients ${ }^{(35)}$, but is frequently ignored. It is defined as an increased sensitivity of the nasal mucosa to environmental, non-specific stimuli (e.g. temperature/humidity changes, smoke, strong odours, exercise and emotional stress), leading to nasal symptoms ${ }^{(41,42)}$. First data with MP-AzeFlu show that it significantly reduces NHR in response to cold dry air ${ }^{(30)}$, which may be responsible for the breakthrough symptoms frequently reported by AR patients. Mechanisms underlying MP-AzeFlu's effect include inhibition of mast cell degranulation and stabilization of the mucosal barrier, thus preventing ingress of allergens to the submucosa. MP-AzeFlu also synergistically abrogated eosinophils in the bronchoalveolar lavage from a murine model of house dust mite-induced allergic inflammation and the combination of AZE + FP (but not either alone) desensitized sensory neurons 
Table 1. summary of panel discussion.

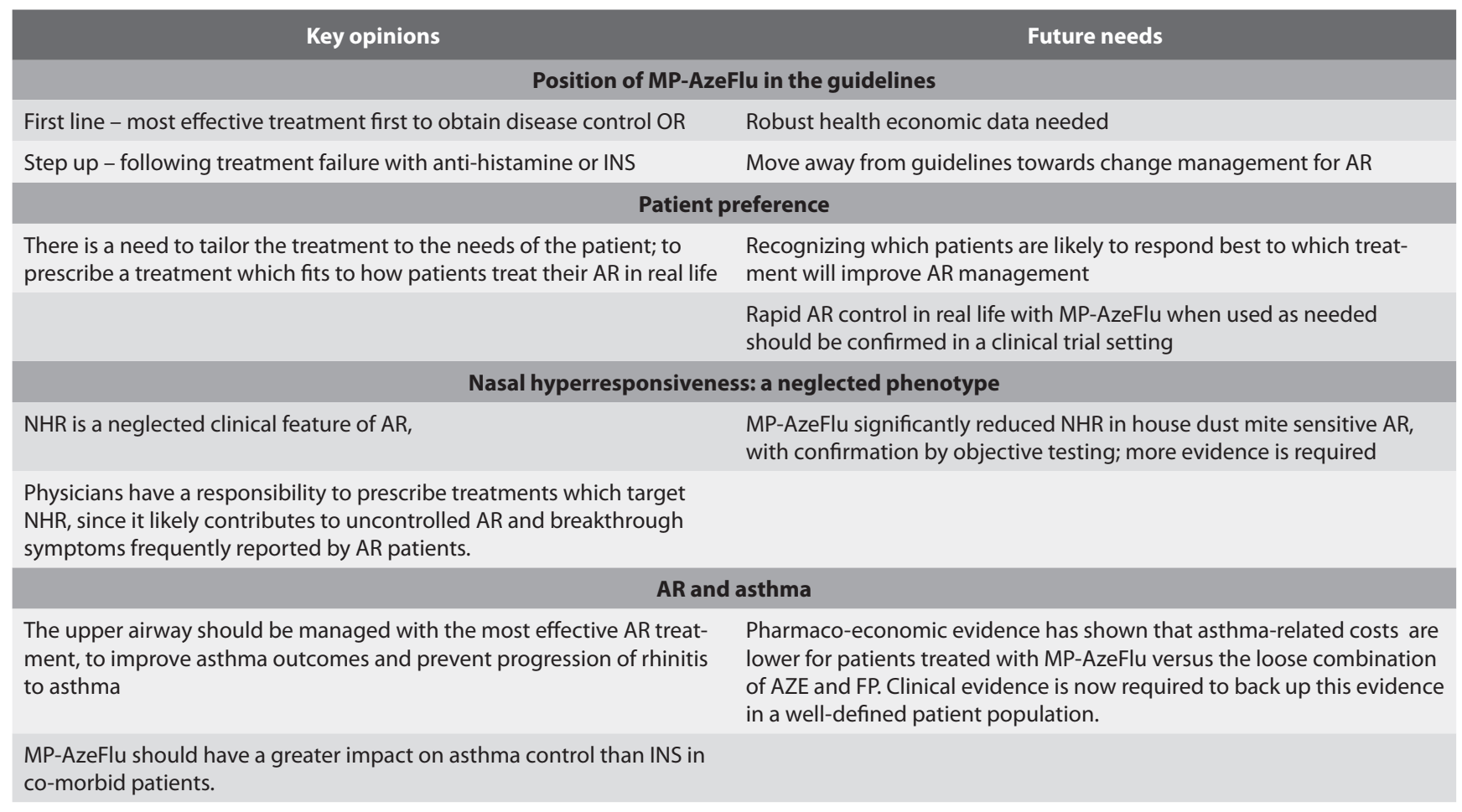

INS: intranasal corticosteroid; AR: allergic rhinitis; NHR: nasal hyperrreactivity; AZE: azelastine; FP: fluticasone propionate

expressing the transient receptor potential A1 and V1 channels ${ }^{(30)}$. Activation of these neuronal channels is responsible for the development of idiopathic rhinitis and non-allergic hyperreactivity ${ }^{(43,44)}$. The panel acknowledged that NHR is clearly a neglected phenotype of $A R$, and that physicians have a responsibility to prescribe treatments which target NHR, since it likely contributes to uncontrolled AR. MP-AzeFlu clearly has a role to play in the successful management of NHR, but more evidence is required (Table 1).

\section{AR and asthma}

Asthma and rhinitis are linked on several levels ${ }^{(45-47)}$. They have a high co-incidence rate ${ }^{(45)}$, share common histological features ${ }^{(48-50)}$, have similar triggers ${ }^{(49,51,52)}$ and inflammatory processes ${ }^{(11,45)}$. Indeed, rhinitis often precedes the development of asthma, and is one of the strongest independent risk factors for the onset and incidence of asthma ${ }^{(53)}$. Furthermore, poor rhinitis control predicts poor asthma control ${ }^{(54-56)}$, and those with both diseases use more asthma medication ${ }^{(55)}$ and have more physician visits and hospitalizations for asthma ${ }^{(57)}$. Given the relationship between AR and asthma, it appears likely that reducing inflammation in the upper airway will improve outcomes in the lower airway for co-morbid patients. Asthma and rhinitis, should, therefore, be optimally treated together ${ }^{(11,}$ 46). The upper airway should be managed with the most effective AR treatment, which should improve asthma outcomes and possibly prevent progression of rhinitis to asthma. INS, but not oral anti-histamines, have a positive impact on many asthma outcomes, such as improved pulmonary function and reduced asthma rescue medication use ${ }^{(58,59)}$. However, INS monotherapy, and even multiple therapies, provide sub-optimal symptom relief for many AR patients with moderate/severe disease ${ }^{(17)}$. More effective AR treatments than INS, such as MP-AzeFlu ${ }^{(7,8)}$ should have a greater impact on asthma control in co-morbid patients. Pharmaco-economic evidence has already shown that asthma-releated costs (both total costs and pharmacy costs) are lower for patients treated with MP-AzeFlu versus the loose combination of AZE and FP ${ }^{(38)}$. Lower asthma pharmacy costs (on MP-AzeFlu), implies less asthma medication usage which is a surrogate marker of asthma control. The panel agreed that clinical evidence is now required to back up this pharmacoeconomic evidence in a well-defined patient population. Such evidence may be gleaned from a real-life study or retrospectiviely by analyzing asthma and AR medication usage in primary care. However, randomized controlled trials are also needed.

\section{Summary of take home messages from panel mem- bers}

AR patients need a treatment like MP-AzeFlu which acts quickly and provides more complete symptom control than INS or multiple therapies, since real life data show that most patients do not take their medication regularly and frequently co-medicate. 
Currently, MP-AzeFlu is the most effective symptomatic treatment for AR and is well tolerated, making it an ideal first-line option which provides patients with what they want (i.e. fast help when they need it). Allergen specific immunotherapy is currently the only disease modifying treatment option. Future avenues of research with MP-AzeFlu include an assessment of its effect in non-allergic rhinitis and also an investigation of any disease modifying effects.

\section{Acknowledgement}

We thank Dr Ruth B Murray (Director, Medscript Ltd, Ireland) for assistance in the production of this article. This debate was funded by an unrestricted educational grant from Mylan.

\section{Authorship contribution}

GS presented the positioning of MP-AzeFlu in AR treatment. All authors contributed to the second Rhinology Future Debate which took place in Brussels in December 2017 thus making a substantial contribution to the content of this article. All authors contributed to the drafting of this work, critically appraised each draft and provided final approval for publication.

\section{Conflict of interest}

GS: has advised, lectured, chaired sessions at scientific meetings and made instructional videos for Mylan. She has been Principal Investigator in a trial involving Dymista.

$\mathrm{JB}$ : is an advisory board member, has provided consultation for and/or received honoraria for meetings and lectures from Chiesi, Cipla, Hikma, Menarini, Mundipharma, Mylan, Novartis, SanofiAventis, Takeda, Teva and Uriach. He also has shares in Kyomed. $\mathrm{CB}$ : is a member of the Dymista advisory board and has given presentations on behalf of Mylan. He is also on the board for Uriach.

WF: received an educational grant from MEDA.

PWH: received unrestricted research grant from Mylan for IIS. EP: No conflict of interest to report.

OP: reports grants and personal fees from ALK-Abelló, grants and personal fees from Allergopharma, grants and personal fees from Stallergenes Greer, grants and personal fees from HAL Allergy Holding B.V./HAL Allergie $\mathrm{GmbH}$, grants and personal fees from Bencard Allergie GmbH/Allergy Therapeutics, grants and personal fees from Lofarma, grants from Biomay, grants from Nuvo, grants from Circassia, grants and personal fees from Biotech Tools S.A., grants and personal fees from Laboratorios LETI/LETI Pharma, personal fees from Novartis Pharma, personal fees from MEDA Pharma, grants and personal fees from Anergis S.A., personal fees from Mobile Chamber Experts (a GA2LEN Partner), personal fees from Pohl-Boskamp, personal fees from Indoor Biotechnologies, grants from Glaxo Smith Kline, outside the submitted work.

DP: board membership with Aerocrine, Amgen, AstraZeneca, Boehringer Ingelheim, Chiesi, Mylan, Mundipharma, Napp, Novartis, and Teva Pharmaceuticals; consultancy agreements with Almirall, Amgen, AstraZeneca, Boehringer Ingelheim, Chiesi, GlaxoSmithKline, Mylan, Mundipharma, Napp, Novartis, Pfizer, Teva Pharmaceuticals, and Theravance; grants and unrestricted funding for investigator-initiated studies (conducted through Observational and Pragmatic Research Institute Pte Ltd) from Aerocrine, AKL Research and Development Ltd, AstraZeneca, Boehringer Ingelheim, British Lung Foundation, Chiesi, Mylan, Mundipharma, Napp, Novartis, Pfizer, Respiratory Effectiveness Group, Teva Pharmaceuticals, Theravance, UK National Health Service, Zentiva; payment for lectures/speaking engagements from Almirall, AstraZeneca, Boehringer Ingelheim, Chiesi, Cipla, GlaxoSmithKline, Kyorin, Mylan, Merck, Mundipharma, Novartis, Pfizer, Skyepharma, and Teva Pharmaceuticals; payment for manuscript preparation from Mundipharma and Teva Pharmaceuticals; payment for the development of educational materials from Mundipharma and Novartis; payment for travel/accommodation/meeting expenses from Aerocrine, AstraZeneca, Boehringer Ingelheim, Mundipharma, Napp, Novartis, and Teva Pharmaceuticals; funding for patient enrolment or completion of research from Chiesi, Novartis, Teva Pharmaceuticals, and Zentiva; stock/stock options from AKL Research and Development Ltd which produces phytopharmaceuticals; owns $74 \%$ of the social enterprise Optimum Patient Care Ltd (Australia and UK) and $74 \%$ of Observational and Pragmatic Research Institute Pte Ltd (Singapore); and is peer reviewer for grant committees of the Efficacy and Mechanism Evaluation programme, and Health Technology Assessment.

\section{References}

1. Hellings PW, Borrelli D, Pietikainen S, et al. European Summit on the Prevention and Self-Management of Chronic Respiratory Diseases: report of the European Union Parliament Summit (29 March 2017). Clin Transl Allergy 2017; 7: 49

2. European Forum for Research \& Education in Allergy and Airway Diseases (EUFOREA): Mission and vision.] Available from http:// www.euforea.eu/about-us/mission-andvision.html.[last accessed March 2018]
3. De Greve G, Hellings PW, Fokkens WJ, Pugin B, Steelant B, Seys SF. Endotype-driven treatment in chronic upper airway diseases. Clin Transl Allergy 2017; 7: 22.

4. Dymista. Summary of Product Characteristics.] Available from https:// www.medicines.org.uk/emc/medicine/27579. [last accessed March 2018]

5. Bousquet J, Bachert C, Bernstein J, et al. Advances in pharmacotherapy for the treatmen tof allergic rhinitis; MP29-02 (a nove formulation of azelastine hydrochloride and fluticasone propionate in an advanced delivery system) fills the gaps. Expert Opin Pharmacother. Exp Opin Pharmacother 2015; 16: 913-928.

6. Carr W, Bernstein J, Lieberman P, et al. A novel intranasal therapy of azelastine with fluticasone for the treatment of allergic rhinitis. J Allergy Clin Immunol 2012; 129: 1282-1289 e10.

7. Meltzer E, Ratner P, Bachert C, et al. Clinically relevant effect of a new intranasal therapy (MP29-02) in allergic rhinitis assessed 
by responder analysis. Int Arch Allergy Immunol 2013; 161:369-377.

8. Price $D$, Shah $S$, Bhatia $S$, et al. A new therapy (MP29-02) is effective for the long-term treatment of chronic rhinitis. J Investig Allergol Clin Immunol 2013; 23: 495-503.

9. Berger WE, Shah S, Lieberman P, et al. Longterm, randomized safety study of MP29-02 (a novel intranasal formulation of azelastine hydrochloride and fluticasone propionate in an advanced delivery system) in subjects with chronic rhinitis. J Allergy Clin Immunol Pract 2014; 2: 179-185.

10. Klimek L, Bachert, C, Stjarne, P, et al. MP-AzeFlu provides rapid and effective allergic rhinitis control in real-life: a panEuropean study. Allergy Asthma Proc 2016; 37: 376-386.

11. Bousquet J, Khaltaev N, Cruz AA, et al. Allergic Rhinitis and its Impact on Asthma (ARIA) 2008 update (in collaboration with the World Health Organization, GA(2)LEN and AllerGen). Allergy 2008; 63 Suppl 86: 8-160.

12. Brozek JL, Bousquet J, Baena-Cagnani $C E$, et al. Allergic Rhinitis and its Impact on Asthma (ARIA) guidelines: 2010 revision. Allergy Clin Immunol 2010; 126: 466-476.

13. Brozek JL, Bousquet J, Agache I, et al. Allergic Rhinitis and its Impact on Asthma (ARIA) guidelines-2016 revision. J Allergy Clin Immunol 2017; 140: 950-958.

14. Scadding GK, Kariyawasam HH, Scadding G, et al. BSACl guideline for the diagnosis and management of allergic and non-allergic rhinitis (Revised Edition 2017; First edition 2007). Clin Exp Allergy 2017; 47: 856-889.

15. Meltzer EO. Allergic Rhinitis: Burden of Illness, Quality of Life, Comorbidities, and Control. Immunol Allergy Clin North Am 2016; 36: 235-248.

16. Bousquet PJ, Bachert C, Canonica GW, et al. Uncontrolled allergic rhinitis during treatment and its impact on quality of life: a cluster randomized trial. J Allergy Clin Immunol 2010; 126: 666-668 e 1-5.

17. Price D, Scadding G, Ryan D, Bachert C, Canonica GW, Mullol J, et al. The hidden burden of adult allergic rhinitis: UK healthcare resource utilisation survey. Clin Transl Allergy 2015; 5:39.

18. Price DB, Scadding G, Bachert C, et al. UK prescribing practices as proxy markers of unmet need in allergic rhinitis: a retrospective observational study. NPJ Prim Care Respir Med 2016; 26: 16033.

19. Bousquet J, Arnavielhe S, Bedbrook A, et al. Treatment of allergic rhinitis using mobile technology with real world data: The MASK observational pilot study. Allergy 2018; doi:10.111/all.13406.

20. Smith P, Price D, Harvey $R$, et al. Medicationrelated costs of rhinitis in Australia: a NostraData cross-sectional study of pharmacy purchases. J Asthma Allergy 2017; 10: 153-161.

21. Anolik R, Mometasone Furoate Nasal Spray With Loratadine Study G. Clinical benefits of combination treatment with mometasone furoate nasal spray and loratadine vs monotherapy with mometasone furoate in the treatment of seasonal allergic rhinitis. Ann Allergy Asthma Immunol 2008; 100: 264-271.

22. Di Lorenzo G, Pacor ML, Pellitteri ME, et al. Randomized placebo-controlled trial comparing fluticasone aqueous nasal spray in mono-therapy, fluticasone plus cetirizine, fluticasone plus montelukast and cetirizine plus montelukast for seasonal allergic rhinitis. Clin Exp Allergy 2004; 34: 259-267.

23. Acaster S, Ali S, Breheny K, Bachert C, Bousquet J, Price D. Treatment Preferences in Patients with Moderate / Severe Seasonal Allergic Rhinitis: Findings of a Discrete Choice Experiment Allergy 2012; 67: A891.

24. Bousquet J, Caimmi DP, Bedbrook A, et al. Pilot study of mobile phone technology in allergic rhinitis in European countries: the MASK-rhinitis study. Allergy 2017; 72: 857-865.

25. Bousquet J, Barbara C, Bateman E, et al. AIRWAYS-ICPS (European Innovation Partnership on Active and Healthy Ageing) from concept to implementation. Eur Respir J 2016; 47: 1028-1033.

26. Bousquet J, Meltzer E, Couroux $P$, et al. Onset of action of the fixed combination intranasal azelastine-fluticasone propionate in an allergen exposure chamber. J Allergy Clin Immunol Pract 2018; doi: 10.1016/j. jaip.2018.01.031.

27. Bousquet J, Schunemann $H$, Arnavielhe $S$, et al. MACVIA clinical decision algorithm in allergic rhinitis in adolescents and adults. J Allergy Clin Immunol 2016; 138: 367-374.

28. Stull DE, Roberts L, Frank L, Heithoff $K$. Relationship of nasal congestion with sleep, mood, and productivity. Curr Med Res Opin 2007: 23: 811-819.

29. Dykewicz MS, Wallace DV, Baroody F, et al. Treatment of seasonal allergic rhinitis: An evidence-based focused 2017 guideline update. Ann Allergy Asthma Immunol 2017; 119: 489-511 e41.

30. Krohn IK, Callebaut I, Alpizar YA, et al. MP2902 reduces nasal hyperreactivity and nasal mediators in patients with house dust mite allergic rhinitis. Allergy 2018; doi:10.111/ all.13349.

31. Canonica GW, Triggiani M, Senna G. 360 degree perspective on allergic rhinitis management in Italy: a survey of GPs, pharmacists and patients. Clin Mol Allergy 2015; 13: 25.

32. Bousquet J, Onorato GL, Bachert C, et al. CHRODIS criteria applied to the MASK (MACVIA-ARIA Sentinel Network) Good Practice in allergic rhinitis: a SUNFRAIL report. Clin Transl Allergy 2017; 7: 37.

33. Al-Abri R. Managing change in healthcare Oman Med J 2007; 22: 9-10.

34. Zuberbier T, Lotvall J, Simoens $\mathrm{S}$, Subramanian SV, Church MK. Economic burden of inadequate management of allergic diseases in the European Union: a GA(2)
LEN review. Allergy 2014; 69: 1275-1279.

35. Segboer $C L$, Holland $C T$, Reinartz SM, et al. Nasal hyper-reactivity is a common feature in both allergic and nonallergic rhinitis. Allergy 2013; 68: 1427-1434.

36. Marple BF, Fornadley JA, Patel AA, et al. Keys to successful management of patients with allergic rhinitis: focus on patient confidence, compliance, and satisfaction. Otolaryngol Head Neck Surg 2007; 136: S107-124.

37. Nathan RA, Meltzer EO, Selner JC, Storms W. Prevalence of allergic rhinitis in the United States. J Allergy Clin Immunol 1997; 99 : S808-814.

38. Harrow B, Sedaghat AR, Caldwell-Tarr A, Dufour R. A Comparison of Health Care Resource Utilization and Costs for Patients with Allergic Rhinitis on Single-Product or Free-Combination Therapy of Intranasal Steroids and Intranasal Antihistamines. J Manag Care Spec Pharm 2016; 22: 14261436.

39. Bousquet J, Schunemann HJ, Fonseca J, et al. MACVIA-ARIA Sentinel Network for allergic rhinitis (MASK-rhinitis): the new generation guideline implementation. Allergy 2015; 70: 1372-1392.

40. Hellings PW, Dobbels F, Denhaerynck K, Piessens M, Ceuppens JL, De Geest S. Explorative study on patient's perceived knowledge level, expectations, preferences and fear of side effects for treatment for allergic rhinitis. Clin Transl Allergy 2012; 2: 9.

41. Van Gerven L, Boeckxstaens G, Hellings P. Up-date on neuro-immune mechanisms involved in allergic and non-allergic rhinitis. Rhinology 2012; 50: 227-235.

42. Salib RJ, Harries PG, Nair SB, Howarth PH. Mechanisms and mediators of nasal symptoms in non-allergic rhinitis. Clin Exp Allergy 2008; 38: 393-404

43. Hox V, Vanoirbeek JA, Alpizar YA, et al. Crucial role of transient receptor potential ankyrin 1 and mast cells in induction of nonallergic airway hyperreactivity in mice. Am J Respir Crit Care Med 2013; 187: 486493.

44. Van Gerven L, Alpizar YA, Wouters MM, et al. Capsaicin treatment reduces nasal hyperreactivity and transient receptor potential cation channel subfamily $\mathrm{V}$, receptor 1 (TRPV1) overexpression in patients with idiopathic rhinitis. J Allergy Clin Immunol 2014; 133: 1332-1339.

45. Bousquet J, Vignola AM, Demoly P. Links between rhinitis and asthma. Allergy 2003; 58: 691-706

46. Scadding G, Walker S. Poor asthma control?-then look up the nose. The importance of co-morbid rhinitis in patients with asthma. Prim Care Respir J 2012; 21: 222-228.

47. Cingi $C$, Gevaert $P$, Mosges R, Rondon C, Hox V, Rudenko M, et al. Multimorbidities of allergic rhinitis in adults: European Academy of Allergy and Clinical Immunology Task Force Report. Clin Transl Allergy 2017; 7: 17 .

48. Slavin RG. The upper and lower airways: 
the epidemiological and pathophysiological connection. Allergy Asthma Proc 2008; 29: 553-556.

49. Simons FE. Allergic rhinobronchitis: the asthma-allergic rhinitis link. J Allergy Clin Immunol 1999; 104: 534-540.

50. Braunstahl GJ. The unified immune system respiratory tract-nasobronchial interaction mechanisms in allergic airway disease. Allergy Clin Immunol 2005; 115: 142-148.

51. Rowe-Jones JM. The link between the nose and lung, perennial rhinitis and asthma--is it the same disease? Allergy 1997; 52: 20-28

52. Durham SR. Mechanisms of mucosal inflammation in the nose and lungs. Clin Exp Allergy 1998; 28 Suppl 2: 11-16.

53. Shaaban R, Zureik M, Soussan D, et al. Rhinitis and onset of asthma: a longitudinal population-based study. Lancet 2008; 372: 10491057.

54. Clatworthy J, Price D, Ryan D, Haughney J, Horne R. The value of self-report assessment of adherence, rhinitis and smoking in relation to asthma control. Prim Care Respir J 2009; 18 : 300-305.

55. Magnan A, Meunier JP, Saugnac C, Gasteau J, Neukirch F. Frequency and impact of allergic rhinitis in asthma patients in everyday general medical practice: a French observational cross-sectional study. Allergy 2008; 63: 292 298.

56. Downie SR, Andersson M, Rimmer J, et al Association between nasal and bronchial symptoms in subjects with persistent allergic rhinitis. Allergy 2004; 59: 320-326.

57. Thomas M, Kocevar VS, Zhang Q, Yin DD, Price D. Asthma-related health care resource use among asthmatic children with and without concomitant allergic rhinitis. Pediatrics 2005; 115: 129-134.

58. Price D, Kemp L, Sims E, et al. Observational study comparing intranasal mometasone furoate with oral antihistamines for rhinitis and asthma. Prim Care Respir J 2010; 19: 266273.

59. Lohia S, Schlosser RJ, Soler ZM. Impact of intranasal corticosteroids on asthma outcomes in allergic rhinitis: a meta-analysis. Allergy 2013; 68: 569-579.1282-1289 e10.

Prof David Price

Academic Primary Care

Division of Applied Health Sciences

University of Aberdeen

Polwarth Building

Foresterhill

Aberdeen AB25 2ZD

United Kingdom

Tel: +65 68029724

E-mail: dprice@opri.sg 